CLINICAL STUDY

\title{
Decreased bone area, bone mineral content, formative markers, and increased bone resorptive markers in endogenous Cushing's syndrome
}

Kristin Godang, Thor Ueland and Jens Bollerslev

Department of Medical Endocrinology, National University Hospital, N-O027 Oslo, Norway

(Correspondence should be addressed to J Bollerslev)

\begin{abstract}
It is well established that chronic excess of glucocorticoids has negative effects on bone and collagen turnover, and that secondary osteoporosis is a known clinical complication of endogenous Cushing's syndrome (CS). The aim of the present study was to evaluate bone dimension and bone mineral content in relation to biochemical markers of bone and collagen turnover, in a consecutive series of 23 patients with endogenous CS (18 with pituitary adenoma and 5 with adrenal tumor; 17 women, 6 men; mean age $39.7 \pm 2.8$ (s.E.m.) and $44.3 \pm 3.1$ years respectively), compared with 23 age-, sex- and body mass index-matched healthy controls.

Bone mineral densities were uniformly reduced in the different regions analyzed: lumbar spine (16.1\%, $P<0.001)$, femoral neck $(15.2 \%, P<0.001)$, total body $(11.5 \%, P<0.001)$, and the subregions of arms $(8.4 \%, P<0.05)$, legs $(10.1 \%, P<0.05)$ and trunk $(15.8 \%, P<0.001)$. Similar results were observed for bone mineral content, although these were less prominent. The calculated area was significantly decreased in trunk $(13.8 \%, P<0.01)$ and total body $(11.6 \%, P<0.05)$.

Serum levels of osteocalcin were significantly decreased $(28 \%, P<0.03)$ in patients with CS. No significant differences were observed for the formative markers carboxyterminal propeptide of type I procollagen and aminoterminal propeptide of type I procollagen. Markers of bone resorption, serum Crosslaps and carboxyterminal cross-linked telopeptide of type I collagen were increased in patients compared with controls, although only significantly for Crosslaps $(P<0.02)$. No correlations between formative and resorptive markers were found in the patients, but in controls, the formative markers were positively correlated with resorptive markers.

In conclusion, bone dimension and bone mineral content of the entire skeleton are found to be decreased in endogenous CS. As judged by biochemical markers of bone remodeling, this is caused by decreased bone formation and an increased bone resorption.
\end{abstract}

European Journal of Endocrinology 141 126-131

\section{Introduction}

Secondary osteoporosis is a well recognized clinical complication to endogenous Cushing's syndrome (CS). Glucocorticoids decrease bone formation and stimulate bone resorption, the latter partly secondary to reduced intestinal calcium absorption (1). In accord, histomorphometric studies in steroid-induced osteopenia have shown decreased bone formation rate and signs of increased bone resorption (2-4). Bone mineral content (BMC) and density (BMD) are markedly decreased in untreated CS, with significant improvement following treatment (5-8). Biochemical markers of bone turnover have consistently shown decreased serum levels of formative parameters $(7,9-12)$, whereas the resorptive markers, so far, have been inconclusive. In a recent study of normal subjects treated with prednisolone (20 mg daily) (13), a prompt decline in formative markers was shown, whereas renal calcium excretion was markedly increased, as was serumparathyroid hormone. Prednisolone decreased the serum marker of bone resorption (carboxyterminal cross-linked telopeptide of type I collagen (ICTP)) but not the urinary markers used (hydroxyproline and crosslinked N-telopeptides of type I collagen).

The aim of the present study was to evaluate bone dimension and BMC, in relation to biochemical markers of bone and collagen turnover, in a consecutive series of patients with endogenous CS.

\section{Patients and methods}

\section{Patients}

Twenty-three consecutive patients with CS (18 with pituitary adenoma and 5 with adrenal tumor), of whom 
17 were women (age $39.7 \pm 2.8$ (s.E.M) years, body mass index (BMI) $29.3 \pm 1.1 \mathrm{~kg} / \mathrm{m}^{2}$ ) and 6 were men $\left(44.3 \pm 3.1\right.$ years, BMI $\left.31.7 \pm 1.2 \mathrm{~kg} / \mathrm{m}^{2}\right)$, were systematically evaluated before the operation and compared with 23 age-, sex- and BMI-matched healthy controls ( 6 men, $48.3 \pm 10.7$ years, BMI $27.7 \pm 3.6 \mathrm{~kg} /$ $\mathrm{m}^{2} ; 17$ women, $41.3 \pm 10.8$, BMI $\left.29 \pm 2.6 \mathrm{~kg} / \mathrm{m}^{2}\right)$. The patients had a typical history and objective findings of CS. The diagnosis was confirmed by abnormal diurnal rhythm of serum cortisol, resistance to a conventional 2-day dexamethasone suppression test, and elevated 24-h urine free cortisol levels. The study was approved by the local ethical committee and conducted according to the Declaration of Helsinki II.

\section{Methods}

BMC, BMD and area measurements $\mathrm{BMC}$ and $\mathrm{BMD}$ were measured in the lumbar spine (L2-L4; anteriorposterior), the left femoral neck and non-dominant forearm using dual-energy X-ray absorptiometry (DEXA) (Lunar DPX-L, software version 1.31, Lunar Corporation, WI, USA). BMC and BMD are expressed in $\mathrm{g}$ and $\mathrm{g} / \mathrm{cm}^{2}$ respectively. For each bone region measured, area in $\mathrm{cm}^{2}$ was determined. The software uses a 'threshold' technique to determine if a data point is either air, tissue or bone. The cuts define a region, separating out data points into each of the defined locations. The software adds up the bone data points for a region and calculates the area based on the sample size of the bone point.

In addition, total body determinations of BMC and BMD were evaluated in 12 of the patients ( 8 woman and 4 men) and 12 age- and BMI-matched controls, and area was calculated for the total body and the subregions of arms, legs and trunk.

All subjects were weighed and measured, without shoes, and while wearing light clothing. All metal objects (buckles, watches, zips and jewelry) were removed before body composition was measured. The entire body of each subject was scanned, beginning at the top of the head. A different scan mode was chosen with respect to each subject's body size, as suggested by the manufacturer's operation manual. Mean measurement time was $20 \mathrm{~min}$. According to the manufacturer, total body determinations of BMC and BMD have a low precision error of $\sim 1$ and $0.5 \%$ respectively, independent of the operator.

Biochemical measurements Blood samples were drawn after an overnight fast, and were centrifuged immediately after collection and serum stored at $-80^{\circ} \mathrm{C}$ until analyzed.

The bone formation markers osteocalcin, carboxyterminal propeptide of type I procollagen (PICP) and aminoterminal propeptide of type I procollagen (PINP), and bone resorption markers serum Crosslaps (s-Crosslaps) and ICTP and the fibroblast marker aminoterminal propeptide of type III procollagen (PIIINP) were determined in addition to serum cortisol. All samples were run in duplicate.

Serum cortisol, serum PIIINP, serum PICP, serum ICTP and serum intact PINP were measured by RIA, using commercial kits from Orion Diagnostica, Espoo, Finland.

In our hands, the intra- and inter-assay coefficients of variation (CVs) for cortisol were 3.3, 2.8 and 2.9\% and $2.9,2.7$ and $3.1 \%$ for low, medium and high levels respectively. Osteocalcin was measured by IRMA, with a commercial kit from Incstar Corporation, Stillwater, MI, USA. The assay measures intact osteocalcin 1-49. The intra-assay CVs were $6.6,5.4$ and $6.1 \%$, for low, medium and high levels. The inter-assay CVs were 11.2 and $4.1 \%$ for medium and high levels. The corresponding intra-assay values for PICP were 4.0, 3.6 and 5.2\%, with an inter-assay CV of 6.9 and $11.2 \%$ for low and high levels. The intra- and inter-assay precision for low, medium and high levels of PINP were, according to the manufacturer, $8.5,8.0$ and $13.7 \%$ and $3.1,4.6$ and $8.2 \%$ respectively.

Degradation products of the C-terminal telopeptides of Type I collagen (Crosslaps) were measured in serum with a commercial ELISA (14) from Osteometer BioTech A/S, Herlev, Denmark. The intra- and inter-assay CVs were both $6.1 \%$. The intra-assay precision for low, medium and high levels of ICTP were 8.7, 2.1 and $4.5 \%$, and inter-assay CVs 3.9 and $5.8 \%$ for low and high levels respectively.

The intra-assay CV for PIIINP was 2.6 with an interassay $\mathrm{CV}$ of $8.7 \%$.

\section{Statistics}

Comparisons between variables in the two groups were performed by Mann-Whitney rank sum test for unpaired data. Relationships between variables were tested using Spearman's rank correlation test and the level of significance was set at $P<0.05$.

\section{Results}

The clinical characteristics of patients and controls are given in Table 1. Serum levels of cortisol were significantly higher in CS $(57 \%, P<0.001)$ compared with controls.

\section{Osteodensitometry}

BMD was significantly decreased in the lumbar spine (16.1\%, $P<0.001)$ and femoral neck (15.2\%, $P<0.001$ ), in patients with CS (Table 2). Total body BMD was significantly decreased in the patient population $(11.5 \%, P<0.001)$, as were the subregions of arms $(8.4 \%, P<0.05)$, legs $(10.1 \%, P<0.05)$ and trunk $(15.8 \%, P<0.001)$. Similar results were observed for BMC, only they were less prominent, and BMC of the arms did not reach significance $(P=0.24)$. The calculated area was significantly decreased in trunk 
Table 1 Clinical characteristics of study subjects. Values are \pm S.E.M. where appropriate.

\begin{tabular}{lccc}
\hline & CS patients & Controls & $P$ \\
\hline Number & 23 & 23 & - \\
Age (years) & $40.8 \pm 2.2$ & $43.0 \pm 2.3$ & $\mathrm{NS}$ \\
Sex & & & \\
$\quad$ Women & 17 & 17 & - \\
$\quad$ Men & 6 & 6 & - \\
Etiology of CS & & - & - \\
$\quad$ Pituitary & 18 & - & - \\
$\quad$ Adrenal & 5 & None & $<0.001$ \\
Hormone substitution & None & $403 \pm 45$ & $\mathrm{NS}$ \\
Cortisol $(08.00 \mathrm{~h})(\mathrm{nmol} / \mathrm{l})$ & $631 \pm 51$ & $28.0 \pm 0.7$ & \\
BMI $\left(\mathrm{kg} / \mathrm{m}^{2}\right)$ & $29.9 \pm 0.9$ &
\end{tabular}

NS, not significant.

(13.8\%, $P<0.01)$ and total body $(11.6 \%, P<0.05)$. The other regions were decreased.

\section{Biochemistry}

Serum levels of osteocalcin were significantly decreased $(28 \%, P<0.03)$ in the patients compared with controls. No significant differences were observed in the other formative markers (Table 3).

Markers of bone resorption, s-Crosslaps and ICTP, were increased in patients compared with controls (38 and $12 \%$ respectively), although only significantly for Crosslaps $(14 \%, P<0.02)$. PIIINP was insignificantly $(P<0.08)$ decreased in the patient population compared with controls.

\section{Relationship between bone and collagen markers}

In patients with endogenous CS, serum osteocalcin was highly correlated with the bone formative marker

Table 2 Osteodensitometry (mean \pm S.E.M.) of lumbar spine and femoral neck in all 23 patients with CS and 23 age-, sex- and BMI-matched healthy controls, and total body determinations in 12 from each group.

\begin{tabular}{|c|c|c|c|}
\hline & CS patients & Controls & $\boldsymbol{P}$ \\
\hline \multicolumn{4}{|l|}{$\operatorname{BMD}\left(\mathrm{g} / \mathrm{cm}^{2}\right)$} \\
\hline Lumbar spine & $1.04 \pm 0.02$ & $1.24 \pm 0.04$ & 0.001 \\
\hline Femoral neck & $0.84 \pm 0.02$ & $0.99 \pm 0.03$ & 0.001 \\
\hline \multicolumn{4}{|l|}{$\mathrm{BMC}(\mathrm{g})$} \\
\hline Lumbar spine & $46.33 \pm 1.81$ & $58.29 \pm 2.73$ & 0.002 \\
\hline Femoral neck & $4.24 \pm 0.12$ & $5.23 \pm 0.21$ & 0.001 \\
\hline \multicolumn{4}{|l|}{ Area $\left(\mathrm{cm}^{2}\right)$} \\
\hline Lumbar spine & $44.4 \pm 1.2$ & $46.8 \pm 1.4$ & NS \\
\hline Femoral neck & $5.08 \pm 0.10$ & $5.30 \pm 0.13$ & NS \\
\hline \multicolumn{4}{|c|}{ Total body $(n=12)$} \\
\hline \multicolumn{4}{|c|}{$\operatorname{BMD}\left(\mathrm{g} / \mathrm{cm}^{2}\right)$} \\
\hline Total & $1.08 \pm 0.02$ & $1.22 \pm 0.03$ & 0.001 \\
\hline Arms & $0.87 \pm 0.02$ & $0.95 \pm 0.03$ & 0.01 \\
\hline Legs & $1.16 \pm 0.03$ & $1.29 \pm 0.04$ & 0.02 \\
\hline Trunk & $0.85 \pm 0.02$ & $1.01 \pm 0.03$ & 0.001 \\
\hline \multicolumn{4}{|l|}{$\mathrm{BMC}(\mathrm{g})$} \\
\hline Total & $2414 \pm 136$ & $3086 \pm 154$ & 0.005 \\
\hline Arms & $344 \pm 27$ & $389 \pm 32$ & NS \\
\hline Legs & $979 \pm 69$ & $1220 \pm 72$ & 0.02 \\
\hline Trunk & $666 \pm 52$ & $955 \pm 58$ & 0.001 \\
\hline \multicolumn{4}{|l|}{ Area $\left(\mathrm{cm}^{2}\right)$} \\
\hline Total & $2224 \pm 106$ & $2514 \pm 87$ & 0.04 \\
\hline Arms & $395 \pm 27$ & $406 \pm 27$ & NS \\
\hline Legs & $834 \pm 42$ & $935 \pm 33$ & NS \\
\hline Trunk & $779 \pm 46$ & $943 \pm 38$ & 0.01 \\
\hline
\end{tabular}

NS, not significant. 
Table 3 Biochemical markers (mean \pm S.E.M.) in 23 patients with CS and 23 age-, sex- and BMI-matched healthy controls.

\begin{tabular}{lccl}
\hline & CS patients & Controls & $\boldsymbol{P}$ \\
\hline Osteocalcin $(\mu \mathrm{g} / \mathrm{l})$ & $2.78 \pm 0.32$ & $3.93 \pm 0.38$ & 0.03 \\
PICP $(\mu \mathrm{g} / /)$ & $134 \pm 11$ & $106 \pm 5$ & NS \\
PINP $(\mu \mathrm{g} / \mathrm{l})$ & $35.7 \pm 4.1$ & $38.9 \pm 3.1$ & $\mathrm{NS}$ \\
S-Crosslaps (pmol/l) & $3974 \pm 389$ & $2878 \pm 188$ & 0.03 \\
ICTP $(\mu \mathrm{g} / \mathrm{l})$ & $3.29 \pm 0.28$ & $2.94 \pm 0.19$ & $\mathrm{NS}$ \\
PIIINP $(\mu \mathrm{g} / \mathrm{l})$ & $3.09 \pm 0.27$ & $3.60 \pm 0.22$ & $\mathrm{NS}$ \\
\hline
\end{tabular}

NS, not significant.

PINP, but not with serum PICP (Table 4). This relationship was also observed in the control group but it was less prominent. PICP and PINP correlated in both the patient and control populations. The bone resorptive markers s-Crosslaps and ICTP correlated in both groups. There were no significant correlations between bone resorptive markers (ICTP and s-Crosslaps), and the bone formative markers (osteocalcin, PICP and PINP) in patients with CS. In the controls, a stronger relationship between resorptive and formative markers was found. Specifically, s-Crosslaps correlated significantly with osteocalcin and PINP, and ICTP with PICP. There were no correlations between bone markers and the non-bone collagen marker, PIIINP, except PICP, where a significant relationship was observed for controls.

\section{Discussion}

In this cross-sectional study of a series of consecutive patients with endogenous CS, compared with a closely matched control group, BMC and BMD were uniformly reduced in the different regions analyzed. This is in accord with previous studies (5-8) and reflects decreased mineral content in both cortical and trabecular bone. Moreover, the study describes decreased bone area, significant in the trunk and entire skeleton.
Bone dimensions, as measured here by the DEXA technique, reflect the continuous periosteal, appositional growth, influenced by endo- and paracrine factors. The decreased bone area found in this study may be caused by the continuous effect of glucocorticoid excess on the periosteal bone formative process; that is, decreased periosteal osteoblastic function. This is in accord with a previous study showing pronounced inhibitory effects of cortisol on DNA synthesis in the periosteum of rat calvariae after long-term exposure (15). This effect was generalized, suggesting effects on both progenitor cells and osteoblasts, indicating failure to replace osteoblasts from the periosteal osteoprogenitor cells. In an analogous fashion, bone dimensions are increased in active acromegaly, which is characterized by a chronic excess of growth hormone, followed by stimulation of periosteal growth (16).

Osteocalcin is the most specific serum marker of bone formation, mainly produced by osteoblasts. It is related to the late mineralization phase of the formative process, although the function of this most prominent, non-collagenic protein of bone is virtually unknown (17-19). The serum level is influenced by renal function (20) but otherwise well correlated with bone formation, as judged by histomorphometry (21) and calcium kinetics (22). This study confirms the findings of previous biochemical investigations $(7,9-12)$ indicating decreased bone formation in endogenous CS. The low serum level of osteocalcin cannot be explained by alteration in renal function, as it did not differ between patients and controls. The two other formative markers used (PICP and PINP) were not significantly different in the patients in this study. The extension peptides of the Type I procollagen are expressed early in the bone formative phase (18). They have so far shown poor sensitivity as formative markers in osteoporosis (23), as in various other metabolic bone diseases, although they are increased in hyperthyreosis and primary hyperparathyroidism

Table 4 Correlations (as correlation coefficient) between bone and collagen markers in 23 patients with CS and 23 age-, sex- and BMI-matched healthy controls.

\begin{tabular}{|c|c|c|c|c|c|}
\hline & Osteocalcin & PICP & PINP & s-Crosslaps & ICTP \\
\hline \multicolumn{6}{|l|}{ CS } \\
\hline PICP & 0.36 & - & - & - & - \\
\hline PINP & $0.72^{\star \star}$ & $0.44^{*}$ & - & - & - \\
\hline s-Crosslaps & -0.12 & 0.22 & -0.07 & - & - \\
\hline ICTP & -0.08 & 0.11 & -0.03 & $0.49^{*}$ & - \\
\hline PIIINP & 0.19 & 0.20 & 0.29 & -0.19 & 0.05 \\
\hline \multicolumn{6}{|l|}{ Controls } \\
\hline PICP & 0.12 & - & - & - & - \\
\hline PINP & $0.44^{*}$ & $0.48^{*}$ & - & - & - \\
\hline s-Crosslaps & $0.44^{*}$ & 0.18 & $0.67^{* *}$ & - & - \\
\hline ICTP & 0.18 & $0.41^{*}$ & 0.36 & $0.43^{*}$ & - \\
\hline PIIINP & -0.03 & $0.45^{\star}$ & 0.37 & -0.07 & 0.35 \\
\hline
\end{tabular}

${ }^{*} P<0.05,{ }^{* *} P<0.001$. 
(24). The tendency of an increased level of PICP, in spite of an expected decrease in this study, as found by others (7), may be explained by decreased hepatic clearance in CS. PICP is eliminated from the circulation by the mannose receptor on liver endothelial cells (25), whereas the N-terminal procollagen (PINP) is cleared by the scavenger receptor (18). The different mode of elimination of the three formative markers may explain the relatively weak correlations between osteocalcin and PICP, and between the two procollagens (Table 4).

Biochemically, bone resorption is normally evaluated by urine analyses. However, we had only the opportunity to run serum markers in this study. The most specific of these, s-Crosslaps (14), was markedly increased in the patient population, whereas ICTP was insignificantly increased. However, the value of ICTP as a true resorption marker has been questioned (26). In accord with our results, the classical, although rather non-specific resorption marker, urinary hydroxyproline has been found to be increased in CS (9). Our finding is substantiated by the correlation analyses (Table 4). Normally, a tight correlation between formative and resorptive markers exists, reflecting the coupling principle between formation and resorption. We found a significant positive correlation between resorptive and formative markers in the controls, as expected. In the patients, however, not even a trend was found. Again, precautions have to be taken against elimination kinetics in the patients. In addition, biochemical markers of bone turnover exhibit intra-individual variation, and stronger correlations might be accomplished if blood sampling was performed on two separate days and a mean value for each marker was used. We acknowledge the cross-sectional design of the study as a limitation, and that long-term longitudinal studies, prospectively following patients after successful surgery, should be performed in the future.

In conclusion, bone dimension and bone mineral content of the entire skeleton is found decreased in endogenous CS. As judged by biochemical markers of bone remodeling, this is caused by decreased bone formation and increased bone resorption. Further histomorphometric analyses is needed to elucidate the pathophysiological mechanism underlying the results.

\section{References}

1 Lukert BP \& Raisz LG. Glucocorticoid-induced osteoporosis: pathogenesis and management. Annals of Internal Medicine $1990112352-364$.

2 Bressot C, Meunier PJ, Chapuy MC, Lejeune E, Edouard C \& Darby AJ. Histomorphometric profile, pathophysiology and reversibility of corticosteroid-induced osteoporosis. Metabolic Bone Disease and Related Research 19791 303-319.

3 Meunier PJ, Dempster DW, Edouard C, Chapuy MC, Arlot M \& Charhon S. Bone histomorphometry in corticosteroid-induced osteoporosis and Cushing's syndrome. Advances in Experimental Medicine and Biology 1984171 191-200.
4 Borelli A, Leite MO, Correa PH, Jorgetti V, Marcondes JA, Batalha JR et al. Bone histomorphometry in Cushing's syndrome. Journal of Endocrinological Investigation 199215 783-787.

5 Lufkin EG, Wahner HW \& Bergstralh EJ. Reversibility of steroidinduced osteoporosis. American Journal of Medicine $1988 \mathbf{8 5}$ 887-888.

6 Manning PJ, Evans MC \& Reid IR. Normal bone mineral density following cure of Cushing's syndrome. Clinical Endocrinology $199236229-234$.

7 Hermus AR, Smals AG, Swinkels LM, Huysmans DA, Pieters GF, Sweep CF et al. Bone mineral density and bone turnover before and after surgical cure of Cushing's syndrome. Journal of Clinical Endocrinology and Metabolism 199580 2859-2865.

8 Wajchenberg BL, Bosco A, Marone MM, Levin S, Rocha M, Lerario AC et al. Estimation of body fat and lean tissue distribution by dual energy X-ray absorptiometry and abdominal body fat evaluation by computed tomography in Cushing's disease. Journal of Clinical Endocrinology and Metabolism 1995802791 2794.

9 Ebeling PR, Peterson JM \& Riggs BL. Utility of type I procollagen propeptide assays for assessing abnormalities in metabolic bone diseases. Journal of Bone and Mineral Research 19927 1243-1250.

10 Piovesan A, Terzolo M, Reimondo G, Pia A, Codegone A, Osella G et al. Biochemical markers of bone and collagen turnover in acromegaly or Cushing's syndrome. Hormone and Metabolic Research $199426234-237$.

11 Sartorio A, Conti A, Ferrero S, Giambona S, Re T, Passini E et al. Evaluation of markers of bone and collagen turnover in patients with active and preclinical Cushing's syndrome and in patients with adrenal incidentaloma. European Journal of Endocrinology 1998138 146-152.

12 Osella G, Terzolo M, Reimondo G, Piovesan A, Pia A, Termine A et al. Serum markers of bone and collagen turnover in patients with Cushing's syndrome and in subjects with adrenal incidentalomas. Journal of Clinical Endocrinology and Metabolism 199782 3303-3307.

13 Gram J, Junker P, Nielsen HK \& Bollerslev J. Effects of short-term treatment with prednisolone and calcitriol on bone and mineral metabolism in normal males. Bone 199823 297-302.

14 Bonde M, Garnero P, Fledelius C, Qvist P, Delmas PD \& Christiansen C. Measurement of bone degradation products in serum using antibodies reactive with an isomerized form of an 8 amino acid sequence of the C-telopeptide of type I collagen. Journal of Bone and Mineral Research 199712 1028-1034.

15 Canalis E. Effect of glucocorticoids on type I collagen synthesis, alkaline phosphatase activity, and deoxyribonucleic acid content in cultured rat calvariae. Endocrinology 1983112 931-939.

16 Ikkos DG, Ntalles K, Velentzas C \& Katsichtis P. Cortical bone mass in acromegaly. Acta Radiologica: Diagnosis $197415134-144$.

17 Brown JP, Delmas PD, Malaval L, Edouard C, Chapuy MC \& Meunier PJ. Serum bone Gla-protein: a specific marker for bone formation in postmenopausal osteoporosis. Lancet 19841 1091-1093.

18 Risteli L \& Risteli J. Biochemical markers of bone metabolism. Annals of Medicine 199325 385-393.

19 Price PA \& Nishimoto SK. Radioimmunoassay for the vitamin K-dependent protein of bone and its discovery in plasma. Proceedings of the National Academy of Sciences of the USA 1980 $772234-2238$.

20 Delmas PD, Wilson DM, Mann KG \& Riggs BL. Effect of renal function on plasma levels of bone Gla-protein. Journal of Clinical Endocrinology and Metabolism 198357 1028-1030.

21 Eriksen EF, Charles P, Melsen F, Mosekilde L, Risteli L \& Risteli J. Serum markers of type I collagen formation and degradation in metabolic bone disease: correlation with bone histomorphometry. Journal of Bone and Mineral Research 19938 127-132.

22 Charles P, Mosekilde L, Risteli L, Risteli J \& Eriksen EF. Assessment of bone remodeling using biochemical indicators of type I collagen synthesis and degradation: relation to calcium kinetics. Bone and Mineral $19942481-94$. 
23 Hassager C, Fabbri-Mabelli G \& Christiansen C. The effect of the menopause and hormone replacement therapy on serum carboxyterminal propeptide of type I collagen. Osteoporosis International 19933 50-52.

24 Rasmussen HB, Teisner B, Gram J, Brixen K, Yde-Andersen E \& Bollerslev J. Serum levels of fetal antigen 2 in hyperthyroidism and primary hyperparathyroidism. APMIS $1992100894-900$.

25 Smedsrod B, Melkko J, Risteli L \& Risteli J. Circulating C-terminal propeptide of type I procollagen is cleared mainly via the mannose receptor in liver endothelial cells. Biochemical Journal $1990271345-350$.
26 Hassager C, Jensen LT, Podenphant J, Thomsen K \& Christiansen $\mathrm{C}$. The carboxy-terminal pyridinoline cross-linked telopeptide of type I collagen in serum as a marker of bone resorption: the effect of nandrolone decanoate and hormone replacement therapy. Calcified Tissue International 199454 30-33.

Received 25 November 1998

Accepted 13 April 1999 